\title{
A study of morbidity and drug utilization pattern in indoor patients of high risk pregnancy at tertiary care hospital
}

\author{
Kamlesh P. Patel*, Harsh M. Joshi, Varsha J. Patel
}

Department of Pharmacology, Smt. N.H.L. Municipal Medical College, Ellisbridge, Ahmedabad-380006, India

Received: 17 June 2013

Accepted: 29 June 2013

\author{
*Correspondence: \\ Dr. Kamlesh P. Patel \\ E-mail: drkamleshp@yahoo.com
}

(C) 2013 Patel KP et al. This is an open-access article distributed under the terms of the Creative Commons Attribution Non-Commercial License, which permits unrestricted non-commercial use, distribution, and reproduction in any medium, provided the original work is properly cited.

\begin{abstract}
Background: Pregnancy represents a special physiological state during which the use of drug is of growing concern due to risk of teratogenicity. High risk pregnancy is common threat to mother and foetus. Therefore, our aim was to study the drug utilization and morbidity pattern in high risk pregnancy in hospitalized pregnant women.

Methods: An observational, prospective study was carried out in 250 patients for 6 months in the tertiary care hospital. Protocol was approved by the Institutional Review Board (IRB). The data were collected in a pre-designed proforma. Data were analysed by using SPSS version 20.0 Software.

Results: Among 250 patients, 19 (7.6\%), 218 (87.2\%) and $13(5.2 \%)$ were of less than 20, 20 to 30 and more than 30 years of age respectively. About $68.8 \%$ women had complained of abdominal pain and $67.6 \%$ had weakness followed by headache / body ache $(47.2 \%)$, oedema $(26.4 \%)$ and vomiting $(18.8 \%)$. Iron $(91.2 \%)$ and calcium $(84.5 \%)$ were the commonest drugs prescribed followed by folic acid $(59.6 \%)$, protein powder $(54.8 \%)$, vitamin $\mathrm{C}(46.8 \%)$ and isoxsuprine (26.6\%). As per FDA Drug Risk Category, Category-A (82.21\%) was most frequently prescribed followed by Category-B (15.64\%) and Category-C (2.15\%). Percentage of drugs prescribed by generic name and from essential drug list was $62.80 \%$ and $80.79 \%$.

Conclusion: Iron, Calcium and Folic acid were most commonly prescribed drugs. There is lesser number of drugs prescribed by generic name suggesting need for sincere efforts to improve situation.
\end{abstract}

Keywords: Drug utilization, High risk pregnancy, WHO core drug prescribing indicators

\section{INTRODUCTION}

Pregnancy is a normal physiological state that may accompany some common conditions which may occur normally due to the physiological changes for which drug treatment may be necessary. Sometimes certain chronic medical conditions like tuberculosis, diabetes etc. may occur during or before pregnancy which are needed to be treated for the benefits of both mother and foetus. However, most studies reporting the drug use during pregnancy found an increasing trend in drug use. ${ }^{1}$

A pregnancy is defined as 'High risk' when there is a likelihood of an adverse outcome to the woman and/or to the baby that is greater than the incidence of that outcome in the general pregnant population. A high risk pregnancy is that with a significant probability for a poor maternal or foetal outcome. High risk patients require sophisticated maternal and foetal surveillance and in many occasions difficult management. A high risk pregnancy can be identified only if the woman has access to prenatal care.

List of conditions that place pregnancy at high risk are such as anaemia, hypertension, diabetes, cardiac disease, multiple pregnancies, oligohydramnios, intra uterine growth retardation, ante partum haemorrhage, eclampsia, post dates pregnancy, human immune deficiency virus infection, asthma and others. ${ }^{2}$ Drugs play an important role in improving human health and promoting well being. However to produce the desired effect, they have 
to be safe, efficacious and have to be used rationally. Safe and efficacious use of drugs prevents morbidity and mortality in mother and foetus. Hence, our objective of the study was to study the morbidity pattern, drug use pattern in indoor patients of high risk pregnancy at Obstetrics and Gynaecology department in a tertiary care teaching hospital; to evaluate the drug use pattern

Using US-FDA Drug Risk Category ${ }^{3}$, WHO core drug prescribing indicators ${ }^{4}$ and to find out the average cost of treatment per patient.

\section{METHODS}

The present study was carried out in obstetrics and gynecology department at a tertiary care teaching hospital in Ahmedabad, India during 6 months period from January 2012 to June 2012. All the patients admitted to obstetrics department were included in our study. The protocol and other documents like proforma, patient information sheet and informed consent form in English and Gujarati were approved by Institutional Review Board (IRB). The study was started after getting written approval from IRB.

The data was collected from all the patients irrespective of age in a pre-designed proforma after taking written informed consent from the patients and/or patient's relatives. The proforma includes patient's demographic details, religion, indoor number, pregnancy duration, provisional diagnosis / chief complaints, investigations and complete prescription. Data of all the 250 patients were analysed by using SPSS version 20.0 Software. Prescription pattern was evaluated by using WHO core drug prescribing indicators and US-FDA Drug Risk Category.

\section{RESULTS}

The demographic data concerning the age of the study population shows that out of total 250 pregnant women, $19(7.6 \%), 218(87.2 \%)$ and $13(5.2 \%)$ were of less than 20,20 to 30 and more than 30 years of age respectively (Figure 1). Out of 250, 8 (3.2\%), 119 (47.4\%) and 123 (49\%) patients were admitted during $1^{\text {st }}, 2^{\text {nd }}$ and $3^{\text {rd }}$ trimester of pregnancy respectively (Figure 1). 121 $(48.4 \%)$ and $129(51.6 \%)$ patients were primiparous and multiparous respectively. Disease pattern showed that anaemia $(47.6 \%)$ and pregnancy induced hypertension (PIH) $(41.6 \%)$ was commonest followed by oligohydramnios $(17.2 \%)$, post dates $(11.6 \%)$, ante partum haemorrhage $(8.4 \%)$, diabetes $(4.8 \%)$, twins $(4 \%)$ and IUGR (3.6\%) (Figure 2). About $68.8 \%$ women have complaint of abdominal pain and $67.6 \%$ had weakness followed by headache/body ache $(47.2 \%)$, oedema (26.4\%) and vomiting (18.8\%). (Table 1) Average number of drugs prescribed was $6.58 \pm 1.4$ (Figure 3). Number of drugs varies with each trimester. In first trimester, 36 drugs prescribed to 8 patients with mean $4.5 \pm 1.2$. In second trimester, 119 patients received 779 drugs with mean $6.54 \pm 3.86$. In third trimester, 123 patients received 622 drugs with mean 5.06 \pm 2.79 (Table 2). Thirteen most frequently prescribed drugs were ferrous fumarate / ascorbate $(91.2 \%)$, calcium carbonate $(84.5 \%)$, folic acid $(59.6 \%)$ and protein powder $(54.8 \%)$ followed by vitamin C $(46.8 \%)$, isoxsuprine (26.6\%), nifedipine (24.0\%), clotrimazole $(18.8 \%)$, ranitidine $(11.6 \%)$, amoxicillin (9.2\%), paracetamol $(8.0 \%)$, essential amino acids $(6.0 \%)$ and insulin (4.8\%) (Figure 4).

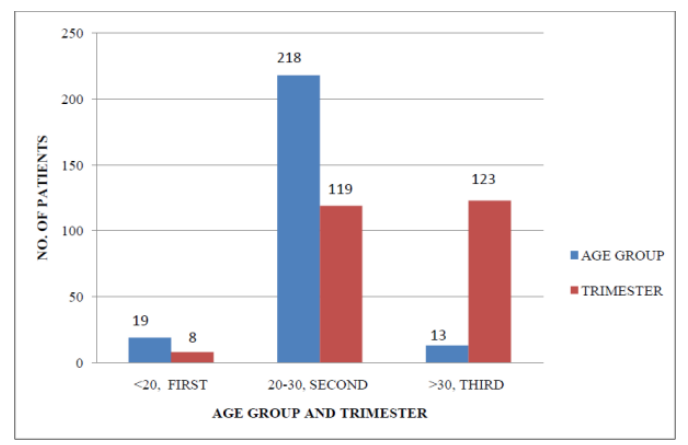

Figure 1: Age group and trimester wise distribution of patients.

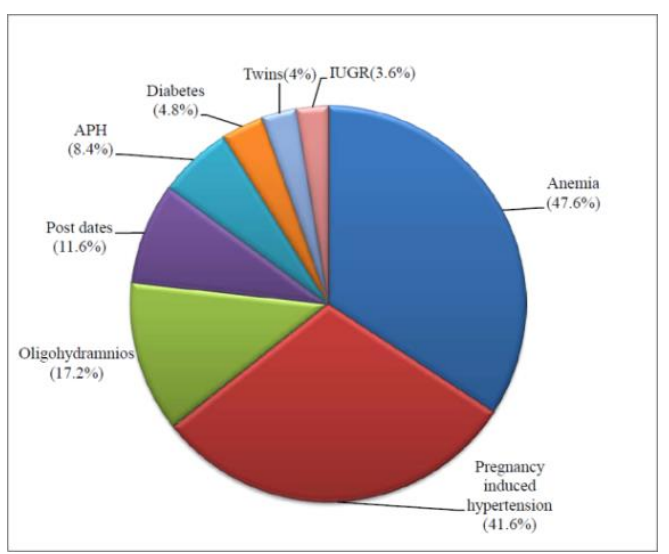

Figure 2: Disease pattern among high risk patients.

Note- One patient may have more than one disease.

APH- Antepartum haemorrhage. IUGR- Intrauterine Growth Retardation

In the first trimester folic acid (87.5\%) was most frequently prescribed followed by ant emetic drug (25\%), iron $(75 \%)$, protein powder $(75 \%)$, paracetamol $(50 \%)$ and antimicrobial drugs $(25 \%)$. In the second trimester iron $(91.0 \%)$, calcium $(89.0 \%)$ and folic acid $(84.9 \%)$ commonly used followed by protein powder $(77.3 \%)$, vitamin C (74.8\%), nifedipine (41.2\%), isoxsuprine $(33.6 \%)$, antifungal drug $(27.7 \%)$, antimicrobial agents $(15.9 \%)$, antacids $(14.3 \%)$ and insulin $(6.7 \%)$. In the third trimester iron $(89.4 \%)$, calcium $(86.1 \%)$, and folic acid $(50.0 \%)$ were most frequently prescribed followed by protein powder $(31.7 \%)$, vitamin $\mathrm{C}(22.7 \%)$, isoxsuprine (20.3\%), nifedipine (15.4\%), essential amino acids $(12.2 \%)$, antifungal drugs $(9.8 \%)$ and betamethasone $(9.8 \%)$ (Table 3). 
Table 1: Morbidity pattern.

\begin{tabular}{|lll|l|}
\hline $\begin{array}{l}\text { Sr. } \\
\text { no. }\end{array}$ & Morbidity Pattern & $\begin{array}{l}\text { No. of } \\
\text { patients }\end{array}$ & Percentage \\
\hline 1. & Abdominal pain & 172 & 68.8 \\
\hline 2. & Weakness & 169 & 67.6 \\
\hline 3. & Headache/Bodyache & 118 & 47.2 \\
\hline 4 & Edema & 66 & 26.4 \\
\hline 5. & Vomiting & 47 & 18.8 \\
\hline 6. & Itching in vagina & 33 & 13.2 \\
\hline 7. & Cough & 21 & 8.4 \\
\hline 8. & Discharge per vagina & 16 & 6.4 \\
\hline 9 & Blurred vision & 14 & 5.6 \\
\hline 10 & Polyuria & 12 & 4.8 \\
\hline 11. & Convulsion & 10 & 4 \\
\hline 12. & Giddiness & 8 & 2.31 \\
\hline
\end{tabular}

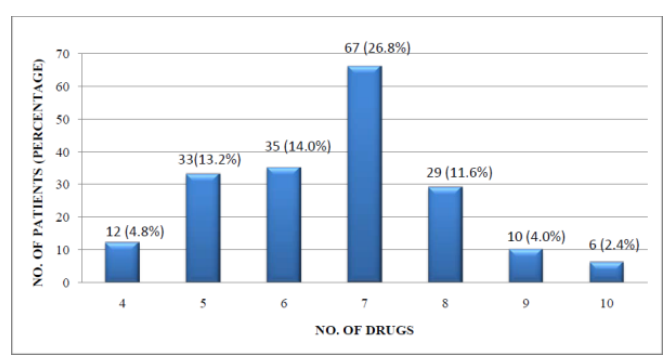

Figure 3: No. of drug wise distribution pattern.

Table 2: Trimester wise number of drugs.

\begin{tabular}{|lllll|}
\hline Trimester & $\begin{array}{l}\text { No. of } \\
\text { Patients }\end{array}$ & $\begin{array}{l}\text { No. of } \\
\text { Drugs }\end{array}$ & $\begin{array}{l}\text { Mean } \\
\text { No. of } \\
\text { Drugs }\end{array}$ & $\begin{array}{l}\text { Standard } \\
\text { Deviation } \\
( \pm)\end{array}$ \\
\hline First & 8 & 36 & 4.5 & 1.20 \\
\hline Second & 119 & 779 & 6.54 & 3.86 \\
\hline Third & 123 & 622 & 5.06 & 2.79 \\
\hline
\end{tabular}

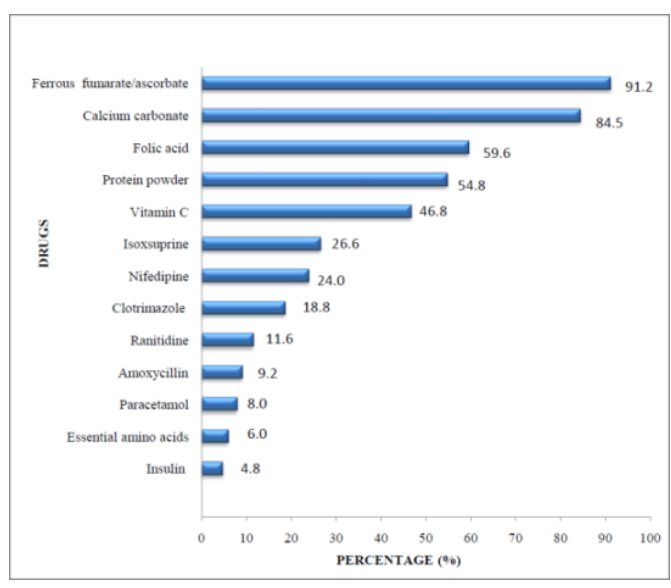

Figure 4: Most frequently prescribed drugs.
Out of 119 patients of anaemia, $82(32.8 \%)$ and 37 $(14.8 \%)$ patients suffered from moderate anaemia $(\mathrm{Hb}-7$ to $10 \mathrm{gm} \%)$ and severe $(\mathrm{Hb}-<7 \mathrm{gm} \%)$ respectively. In moderate anaemia, iron salts were given in most of patients as to overcome the need of increased iron requirement during pregnancy. Ferrous fumarate and ferrous ascorbate were the most commonly used iron salts. Ferrous fumarate and Ferrous ascorbate was prescribed to $65(80.0 \%)$ and $14(20.0 \%)$ patients in the dose of $300 \mathrm{mg}$ and $100 \mathrm{mg}$ once or twice a day respectively according to haemoglobin. Iron sucrose was given to $15(6 \%)$ patients. After dilution in normal saline, it was given intravenously slowly. In moderate and severe anaemia 3 and 10 patients were prescribed iron sucrose injection respectively. In severe anaemia, packed cell volume (PCV) was given to $27(10.8 \%)$ patients. After each Packed Cell Volume (PCV), injection furosemide $(40 \mathrm{mg})$ was given intravenously.

In PIH patients, nifedipine was given to 60 (24.0\%) patients. It was given in $10 \mathrm{mg}$ orally twice or thrice a day according to blood pressure. Labetalol was prescribed to $42(16.8 \%)$ patients. Most of patients were given $100 \mathrm{mg}$ twice a day orally and dose was adjusted according to blood pressure. Methyldopa had been given to $32(12.8 \%)$ patients with dose of $250 \mathrm{mg}$ twice or thrice a day according to blood pressure. Magnesium sulphate was prescribed to $10(4 \%)$ patients who had severe or impending eclampsia, with a dose of $4 \mathrm{gm} \mathrm{I.V}$. diluted in $12 \mathrm{ml}$ normal saline and $10 \mathrm{gm}$ intramuscular with $5 \mathrm{gm}$ in each buttock. Essential amino acids like linoleic acid and linolenic acid were given orally daily to $15(6 \%)$ patients of oligohydramnios. Arginine sachet contains arginine amino acid was prescribed to $11(6 \%)$ patients orally once a day according to severity of oligohydramnios. Out of $12(4.8 \%)$ patients of diabetes, insulin was given subcutaneously according to blood sugar and diabetic profile. Combination of short and intermediate acting insulin (soluble + isophane insulin (30/70)) was given. Two thirds of dose was given before breakfast and a third before dinner. $9(3.6 \%)$ patients were diagnosed IUGR. Essential amino acids like linoleic acid and linolenic acid were given orally daily to 4 patients. Arginine sachet was prescribed to 5 patients orally once a day according to severity of IUGR. Hermin (Brand Name) injection $(500 \mathrm{ml})$ contains combination of various amino acids was also given to 2 patients intravenously alternate day. Cost of total duration of drug therapy per patient was 303.2 ( \pm 30.96$)$ INR (Indian Rupees).

In the present study majority of drugs were from category A $82.21 \%$ which is the safest category followed by category B $15.64 \%$ category C $2.15 \%$ and category D $0.00 \%$ (Figure 5). World Health Organization (WHO) has given three types of indicators namely prescribing indicators, patient care indicators and facility indicators as determinant of rational prescribing. Out of this, in the present study, only prescribing indicators has been used. (Table 4). 
Table 3: Trimester wise distribution of prescribed drugs/drug groups.

\begin{tabular}{|lllll|}
\hline Sr. No. & Drugs & $\begin{array}{l}\text { First Trimester } \\
\text { No. of patients }(\%)\end{array}$ & $\begin{array}{l}\text { Second Trimester } \\
\text { No. of patients (\%) }\end{array}$ & $\begin{array}{l}\text { Third Trimester } \\
\text { No. of patients (\%) }\end{array}$ \\
\hline 1. & Iron & $6(75.0 \%)$ & $112(91.0 \%)$ & $110(89.4 \%)$ \\
\hline 2. & Calcium & - & $105(89.0 \%)$ & $106(86.1 \%)$ \\
\hline 3. & Folic acid & $7(87.5 \%)$ & $101(84.9 \%)$ & $61(50 \%)$ \\
\hline 4. & Protein powder & $6(75.0 \%)$ & $92(77.3 \%)$ & $39(31.7 \%)$ \\
\hline 5. & Vitamin C & - & $89(74.8 \%)$ & $28(22.7 \%)$ \\
\hline 6. & Nifedipine & $2(25.0 \%)$ & $49(41.2 \%)$ & $19(15.4 \%)$ \\
\hline 7. & Uterine relaxant & - & $40(33.6 \%)$ & $25(20.3)$ \\
\hline 8. & Antifungal drug & $2(25.0 \%)$ & $33(27.7 \%)$ & $12(9.8 \%)$ \\
\hline 9. & Antimicrobial agent & $2(25.0 \%)$ & $19(15.9 \%)$ & $8(6.5 \%)$ \\
\hline 10. & Antacids & $2(25.0 \%)$ & $17(14.3 \%)$ & $8(6.5 \%)$ \\
\hline 11. & Insulin & - & $8(6.7 \%)$ & $4(3.3 \%)$ \\
\hline 12 & Antiemetic drugs & $6(25.0 \%)$ & $16(13.6 \%)$ & $10(8.8 \%)$ \\
\hline 13 & Paracetamol & $4(50.0 \%)$ & $4(3.4 \%)$ & $12(9.8 \%)$ \\
\hline 14 & Betamethasone & - & - & $12(9.8 \%)$ \\
\hline 15 & Essential amino acids & - & - & $15(12.2 \%)$ \\
\hline
\end{tabular}

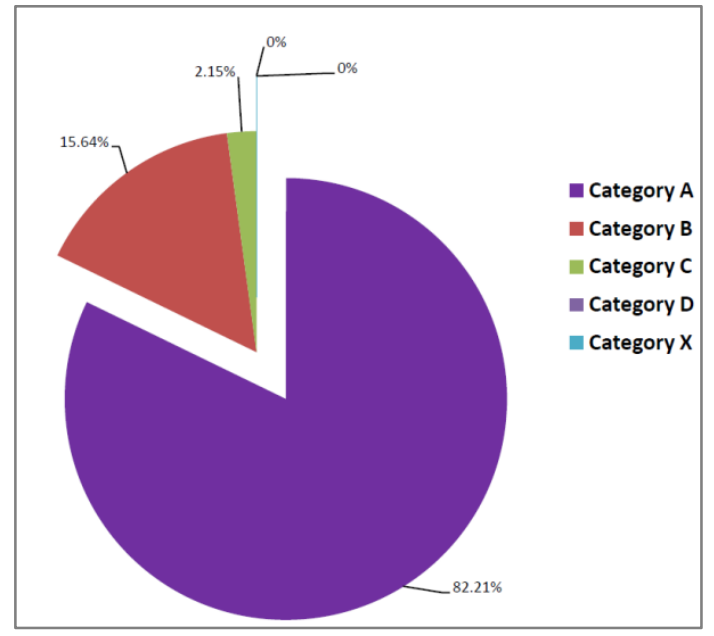

Figure 5: FDA drug risk category wise prescription pattern.

\section{DISCUSSION}

In the present study, the demographic data demonstrated that baseline study population was comparable to earlier study done in Kathmandu in which $90 \%$ of women were under 30 years of age. ${ }^{5}$ But it is not in accordance with the study carried out in Australia showed women less than 20, 20 to 30 and more than 30 years of age were $4 \%$, $70 \%$ and $26 \%$ respectively. ${ }^{6}$ Trimester wise distribution of the study population is similar with previous study ${ }^{5}$ in which most of patients were in second trimester. Disease pattern is not in accordance with study done in Mexico in which preeclampsia, postpartum haemorrhage, and chronic hypertension were common. ${ }^{7}$ Morbidity pattern is in accordance with studies done in Bangladesh ${ }^{8}$ and Netherlands ${ }^{9}$ but different than one study. ${ }^{5}$

Table 4: WHO core drug prescribing indicators.

\begin{tabular}{|c|c|c|}
\hline $\begin{array}{l}\text { Sr. } \\
\text { No. }\end{array}$ & Indicator & Value \\
\hline 1. & $\begin{array}{l}\text { Average number of drugs per } \\
\text { prescription }\end{array}$ & 6.58 \\
\hline 2. & $\begin{array}{l}\text { Percentage of drugs prescribed } \\
\text { by generic name }\end{array}$ & 62.80 \\
\hline 3. & $\begin{array}{l}\text { Percentage of encounters with } \\
\text { antibiotic prescribed }\end{array}$ & 13.20 \\
\hline 4. & $\begin{array}{l}\text { Percentage of encounters with } \\
\text { an injection prescribed }\end{array}$ & 25.29 \\
\hline 5. & $\begin{array}{l}\text { Percentage of drugs prescribed } \\
\text { from essential drug list }\end{array}$ & 80.79 \\
\hline 6. & $\begin{array}{l}\text { Percentage of drugs prescribed } \\
\text { from hospital drugs list }\end{array}$ & 32.50 \\
\hline
\end{tabular}

In the present study, average number of drugs prescribed was $6.58 \pm 1.4$ as majority of patients had more than one disease. Iron, calcium, vitamin $\mathrm{C}$ and protein powder were commonly used along with treatment of high risk 
condition. Number of drugs varies with each trimester. In first trimester, mean number of drugs prescribed were 4.5 \pm 1.2 . Most of drugs have teratogenic effects in first trimester so average number of drugs per patient is less than other trimesters. In second trimester mean no. of drugs were $6.54 \pm 3.86$. In third trimester mean number of drugs were $5.06 \pm 2.79$.

Oligohydramnios, post dates; APH and IUGR were common in third trimester. In such conditions normal delivery or caesarean section had been done after two or three days, so less number of drugs prescribed than second trimester. On applying the Kruskal-Wallis Test (non-parametric ANOVA) $\mathrm{Kw}=12.321$ and the mean number of drugs during different trimesters were not significant $(\mathrm{P}=0.940$ at $99 \%$ confidence interval).

Poor dietary status reflected by low socio-economic status makes micronutrient deficiency both clinical and sub clinical. ${ }^{10}$ Repeated pregnancy is also contributing factor for poor nutritional status of the mother. All these factors deplete the micronutrient stores of the mother, to the extent that she becomes anaemic even in the first trimester. This brings adverse outcome for mother and foetus. ${ }^{11,12}$ Hence in our study iron, calcium, and protein powder were given to $91.2 \%, 84.5 \%$, and $54.8 \%$ patients (Figure 4). Preconception folic acid supplementation can prevent neural tube defects and other congenital abnormalities of the cardiovascular system, urinary tract and limb deficiencies of foetus. ${ }^{13}$ So folic acid was prescribed to $59.6 \%$ patients. Vitamin $\mathrm{C}$ increases the absorption of iron from non-animal foods such as spinach and also plays a role in the storage of iron in major organs like liver. ${ }^{14}$ Vitamin $\mathrm{C}$ therefore aids the body in the efficient use of folic acid and iron. ${ }^{15}$ Vitamin $\mathrm{C}$ was prescribed to $46.8 \%$ patients in our study.

Iron deficiency is one of the most common nutritional disorders in developing countries. ${ }^{16}$ It is an important preventable cause of maternal and perinatal morbidity and mortality. Common complaints were weakness, fatigue, dyspnea and headache. A much higher incidence of anemia $(47.6 \%)$ is recorded in present study which is in accordance with study done in Bangladesh (49\%). ${ }^{17} \mathrm{It}$ is less than one study done in Uganda $(84.4 \%)^{18}$ but more than one study done in Pakistan $(40 \%) .{ }^{19}$ In moderate anemia, iron salts were given in most of patients as to overcome the need of increased iron requirement during pregnancy. Ferrous fumarate and Ferrous ascorbate was prescribed in $144(57.6 \%)$ and $45(18 \%)$ patients which is similar to other studies in United States $(72 \%)^{19}$, Switzerland $(65 \%)^{20}$, West Nepal $(72.8 \%)^{21}$ and Egypt $(86 \%)^{22}$ But less than one study. ${ }^{23}$ Injectable iron like iron sucrose was prescribed to moderate and severe anemia when oral iron was not tolerated and gives faster response. Intravenous $\mathrm{PCV}$ was given to patients of severe anemia in late pregnancy.

In PIH, the most commonly prescribed antihypertensive agents were given alone or in combination with nifedipine (24.4\%), labetalol (16.8\%) and methyldopa $(12.8 \%)$. These are different than previous study in which methyldopa was most commonly prescribed followed by nifedipine and hydralazine. ${ }^{24}$ Magnesium sulphate was given to those patients, which were suffering from eclampsia. This is similar with previous study done in Egypt. ${ }^{25}$ Wherever needed, a combination of drugs was used for better reduction in blood pressure. This improves patient compliance and decreases PIH with fewer adverse events. $^{26}$

Oligohydramnios has also been treated with amino acids infusion. ${ }^{27}$ The treatment course involved daily infusions of amino acid solution with/without $10 \%$ glucose. Daily intravascular foetal nutrition may significantly improve both foetal condition and foetal weight gain in oligohydramnios. ${ }^{28}$

Cost of total duration of drug therapy per patient was 303.2 ( \pm 30.96$)$ INR (Indian Rupees). As less (32\%) number of drugs prescribed from hospital supply, average cost of therapy is high.

Now a days metformin and glyburide used for treatment of gestational diabetes, but high numbers of patients need to discontinue and switch over to insulin. ${ }^{29,30}$ In our study insulin was given to all patients of gestational diabetes. As per guidelines, insulin combination of short and intermediate acting insulin was used in 12 patients. Comparing the drug risk categories for pregnancy, introduced by US food and drug administration (FDA), in the present study majority of drugs were from category A $82.21 \%$ which is the safest category followed by category B $15.64 \%$ category C $2.15 \%$ and category D $0.00 \%$. No drug were prescribed from category $\mathrm{X}$ which are absolutely contraindicated in pregnancy (Figure 5). The similar pattern of category distribution was seen in the study done in Netherland in which from category A $81.7 \%$ category B $10.9 \%$, category C $6.3 \%$ category D $1.1 \%$, category $\mathrm{X} 0.0 \%{ }^{31}$ There are reports of use of potentially harmful drug from category $\mathrm{X}$ drug during pregnancy from other developed and underdeveloped countries of the world. ${ }^{32}$ In a retrospective, register based cohort study in Finland, it was found that $20.4 \%$ of women purchased at least one drug classified as potentially harmful during pregnancy and $3.4 \%$ purchased at least one drug classified as clearly harmful. ${ }^{33}$ In a study from Bratislava and Nitra, it was reported that a vast majority of prescribed drugs during pregnancy, belonged to category $C{ }^{34}$ So from the above data we can say that the prescription habit in our set up is quite safe.

Percentage of drugs prescribed by generic name is $62.80 \%$. This shows a greater tendency to prescribe by generic name rather than by brand name. Most of the patients attending the teaching hospitals belong to the lower socio economic classes, so tendency to prescribe by generic name may influence the compliance of patients by affecting the cost. Percentage of encounters 
with antibiotic prescribed is $13.20 \%$ mainly due to respiratory tract infection during pregnancy. Amoxicillin is used in such conditions. Percentage of encounters with an injection prescribed $25.29 \%$. Injectable preparations are used for anaemia, eclampsia, oligohydramnios and IUGR. Percentage of drugs prescribed from essential drugs list is $80.79 \%$. As high rates of drugs prescribe from essential drugs list, it suggests rationality of drug use pattern. Percentage of drugs prescribed from hospital drug list is $32.50 \%$. So more than $60 \%$ of drugs were prescribed from outside the hospital. The reason may be unavailability of the necessary drugs in hospital pharmacy or greater influence of the pharmaceutical companies on the prescriber. It may increase the overall cost of drug therapy.

\section{CONCLUSION}

Abdominal pain and weakness were commonest complaints. Disease pattern showed that anaemia and PIH were commonest. Overall prescribing habit in this set-up is appropriate and rational to a large extent. But there is lesser number of drugs prescribed by generic name suggesting need for sincere efforts to improve situation. This is the preliminary study and further studies are required to find out broader evaluation of the hypolipidemic agents. Hence, such periodic studies are further required in diverse environment, social, educational and cultural conditions, so that the therapeutic guidelines could be revised accordingly to give proper care to the community.

\section{ACKNOWLEDGEMENTS}

We are highly thankful to our Dean, Dr. Pankaj Patel and Head of Department of Obstetrics and Gynaecology, Dr. Manish Jadav for permitting us to carry out the study and collect data.

Funding: None

Conflict of interest: Not declared

Ethical approval: The study was approved by the Institutional Review Board

\section{REFERENCES}

1. Nordeng H, Eskild A. Nesheim BI, Jacobsen G. Drug use in pregnancy among parous scandinavian women. N J Epidem 2001; 11: 97-103.

2. Beers, Mark H. "High-Risk Pregnancies." In The Merck Manual of Diagnosis and Therapy. Rahway, NJ: Merck Research Laboratories, 2004.

3. Frankos VH. FDA Perspectives on the use of teratology data for human risk. Assessment Fundam Appl Toxicol 1985;5:615-25.

4. World Health Organization. How to investigate drug use in health facilities, selected drug use indicators, WHO/DAP/93.1. Geneva: World health Organization, 1993, P:10.
5. Smith JB, Lakhey B, Thapa S, Rajbhandari S, Neupane S Maternal morbidity among women admitted for delivery at a public hospital in Kathmandu. JNMA J Nepal Med Assoc. 1996; 34(118-119):132-40.

6. Tim Badgery-Parker, Jane B Ford, Mary G Jenkins, Jonathan M Morris and Christine L Roberts Patterns and outcomes of preterm hospital admissions during pregnancy in NSW, 2001-2008. Med J Aust 2012; 196 (4): 261-265.

7. Hernandez - Diaz S, Werler MM, Louik C. Risk of gestational hypertension in relation to folic-acid supplementation during pregnancy. Am J Epidemiol 2002; 156: 806-12.

8. Fauzia Akhter Huda, Anisuddin Ahmed, Sushil Kanta Dasgupta, Musharrat Jahan. Profile of Maternal and Foetal Complications duringLabour and Delivery among Women Giving Birth in Hospitals in Matlab and Chandpur, Bangladesh. J Health Popul Nutr 2012 Jun;30(2):131-142.

9. Evers AC, Brouwers HA, Hukkelhoven CW, Nikkels PG, Boon J, van Egmond-Linden A, Hillegersberg J, Snuif YS, Sterken-Hooisma S, Bruinse HW, Kwee A. Perinatal mortality and severe morbidity in low and high risk term pregnancies in the Netherlands: prospective cohort study. BMJ. 2010 Nov 2;341.

10. Bondevik GT, Lie RT, Ulstein M, Kvale G. Maternal hematological status and risk of low birth weight and preterm delivery in Nepal. Acta Obstet Gynaecol Scand 2001; 80:402-8.

11. Abel R, Rajaratnam J, Gnanasekarana VJ, Jayaraman P. Prevalence of anemia and iron deficiency in three trimesters in Rural Vellare District, South India. Trop Doct 2001; 31: 86-9.

12. Milman N, Bergholt T, Byg KE, Eriksen L, Graudal $\mathrm{N}$. Iron status and iron balance during pregnancy. A critical re-appraisal of iron supplementation. Acta Obstet Gynaecol Scand 1999; 78: 749-57.

13. Czeizel AE, Dudas I. Prevention of the first occurrence of neural-tube defects by periconceptional vitamin supplementation. N Eng J Med 1992; 327:1832-5.

14. Shu EN, Ogbodo SO. Role of ascorbic acid in the prevention of iron-deficiency anaemia in pregnancy. Biomedical Research. 2005;16(1):40-44.

15. Ohnston CS, Meyer CG, Srilakshmi JC. Vitamin C elevates red blood cell glutathione in healthy adults. Am J Clin Nutr. 1993 Jul;58(1):103-5.

16. Mah-e-Munir Awan, Muhammad Aftab Akbar, . Misbahul Islam Khan, A study of anemia in pregnant women of railway colony, Multan. Pakistan J Med Res 2004;43:240-5.

17. Ahmed F. Anemia in Bangladesh: a review of prevalence and etiology of anemia. Public Health Nutr 2000; 3: 385-93.

18. Kiwanuka GN, Isharaza WK, Mahmoud S. Iron status of pregnant women at first antenatal booking in Mbara University Teaching Hospital. Trop Doct 2000; 29: 228-30. 
19. Cogswell ME, Kettel-Khan L, Ramakrishnan U. Iron supplement use among women in the United States: science, policy and practice. J Nutr. 2003 Jun; 133(6):1974-1977.

20. Hess SY, Zimmermann MB, Brogli S, Hurrell RF. A national survey of iron and folate status in pregnant women in Switzerland. Int J Vitam Nutr Res. 2001 Sep; 71(5):268-273.

21. Das B, Sarkar C, Datta A, Bohra S. A study of drug use during pregnancy in a teaching hospital in western Nepal. Pharmacoepidemiol Drug Saf. 2003 Apr-May; 12(3):221-225.

22. Rizk MA, Abdel-Aziz F, Ashmawy AA, Mahmoud AA, Abuzeid TM. Knowledge and practices of pregnant women in relation to the intake of drugs during pregnancy. J Egypt Public Health Assoc. 1993; 68(5-6):567-591.

23. Moradi, S. Mohammadi, A. A. Kadiva and S. J. Masoumi. Knowledge and practice of pregnant women in fars province about intake of iron supplements. Acta Medica Iranica 2007;45:299-304.

24. MK Omole, AI Akanji Pharmacotherapy of Hypertension in pregnancy in a Secondary Hospital in South West Nigeria. Nigerian Journal of Pharmaceutical Research 2003;8:1-11.

25. Aal DE, Shahin AY, Management of eclampsia at Assiut University Hospital, Egypt. Int J Gynaecol Obstet. 2012 Mar;116(3):232-6.

26. Jangra Sarita, Bhyan Bhupinder Evaluation of Antihypertensive Therapy of Pregnancy Induced Hypertensive Patients in Mahila Chiktsalaya, Jaipur. JPSBR 2012;2:5-10.

27. Malhotra B, Deka D. Duration of the increase in amniotic fluid index (AFI) after acute maternal hydration. Arch Gynecol Obstet. 2004 Mar; 269 (3): 173-5.

28. Tchirikov M, Kharkevich O, Steetskamp J, Beluga M, Strohner M. Treatment of Growth - Restricted Human Fetuses with Amino Acids and Glucose Supplementation through a Chronic Fetal Intravascular Perinatal Port System. Eur Surg Res. 2010 Aug 20;45(1):45-49.

29. Gilson G, Murphy N. Comparison of oral glyburide with insulin for the management of gestational diabetes mellitus in Alaska Native women. Am J Obstet Gynecol 2002;167:187-90.

30. Conway DL, Gonzales O, Skiver D. Use of glyburide for the treatment of gestational diabetes: the San Antonio experience. J Matern Fetal Neonatal Med 2004;15:51-5.

31. Bakker MK, Jentink J, Vroom F, Van Den Berg PB, De Walle HE, De Jong - Van Den Berg LT. Drug prescription pattern before during and after pregnancy for chronic, occasional and pregnancy related drugs in the Netherlands. $\mathrm{Br} \mathrm{J}$ Obstet Gynecol 2006;113:559-68.

32. Andrade SE, Gurwitz JH, Davis RL, Chan KA et al. Prescription drug use in pregnancy. Am J Obstet Gynecol 2004;191:398-407.

33. Malm H, Martikainen J, Kalukka T, Neuvonen PJ. Prescription of hazardous during pregnancy. Drug Saf 2004;27:899-908.

34. Tisonova J, Magulova L, Goboova $\mathrm{M}$, et al. Consultation activity of two Slovak Centres for pharmacotherapy during pregnancy and lactation. Cas Lek Lesk 2006;145:154-9.

DOI: $10.5455 / 2320-1770$. ijrcog20130922

Cite this article as: Patel KP, Joshi HM, Patel VJ.

A study of morbidity and drug utilization pattern in indoor patients of high risk pregnancy at tertiary care hospital. Int $\mathbf{J}$ Reprod Contracept Obstet Gynecol 2013;2:372-8. 